\author{
Samir Jaber \\ Giuseppe Citerio \\ Daniel Talmor
}

\section{Intensive Care Medicine launches a call for papers on perioperative critical care}

Received: 3 April 2015

Accepted: 20 April 2015

Published online: 22 May 2015

(C) Springer-Verlag Berlin Heidelberg and ESICM 2015

\section{S. Jaber (『)}

Intensive Care Unit and Transplantation, Department of Anesthesia and Critical Care B (DAR B), Hôpital Saint Eloi, CHU Montpellier, 80, avenue Augustin Fliche, INSERM U1046, 34295 Montpellier, Cedex 5, France

e-mail: s-jaber@chu-montpellier.fr

\section{G. Citerio}

Department of Health Science, University of Milan-Bicocca, Monza, Italy

\section{G. Citerio}

Neurointensive Care, Department of Emergency and Intensive Care, San Gerardo Hospital, Monza, Italy

\section{Talmor}

Department of Anesthesia, Critical Care and Pain Medicine, Beth Israel Deaconess Medical Center, Harvard Medical School, Boston, MA, USA

The practice of perioperative medicine is one of the most illustrative approaches in medicine of the famous proverb "prevention is better than cure". Modern "perioperative critical care" describes the medical care of patients at high risk from the time of the first anesthesia consultation, which evaluates risk factors for postoperative complications through the operative period and eventually to full recovery. This pathway may include an intensive care unit (ICU) stay [1]. Contrary to the management of typical patients admitted to medical ICUs, where admissions are largely unplanned, the aim of perioperative medicine is to optimize the management of the surgical patient and to avoid ICU admission if possible. If admission to the ICU is necessary, it is often planned and careful preoperative assessment and intraoperative care can lead to improved outcome. In the practice of perioperative medicine, the surgeon, anesthesiologists, intensivists, and medical consultants all work in concert for the patient's benefit.

It is estimated that more than 230 million patients per year undergo a surgical procedure, often requiring general anesthesia with endotracheal intubation and controlled mechanical ventilation [2]. Although successful surgery is a necessary condition for satisfactory postoperative outcomes, the benefits of any surgical procedure may be mitigated by the development of postoperative complications. Cardiovascular and respiratory postoperative complications are a leading cause of increased morbidity and mortality [3]. These postoperative complications are often associated with ICU admission, prolonged ICU and hospital stay, and increased health care utilization and costs. Identification of patients with high risk of postoperative complications is a challenge in all surgical specialities $[4,5]$. Improved preoperative identification can lead to preoperative, intraoperative, and postoperative optimization of care and result in reduced morbidity and mortality. Evidence supporting best practices in perioperative medicine is expanding, though historically this field has been directed by common practice and experience.

Modern critical care was founded by European anesthesiologists taking the skills learned in the operating room (OR) and applying them to the victims of the polio epidemics of the 1950s [6]. In the last decade, lessons learned in the modern ICU are being taken back to the OR. This cross-pollination between the ICU and the OR benefits patients in both of these areas, reducing morbidity and mortality. The OR and the ICU are similar environments and indeed anesthetic care can be viewed as the short-term, intensive care of a single patient. In both 


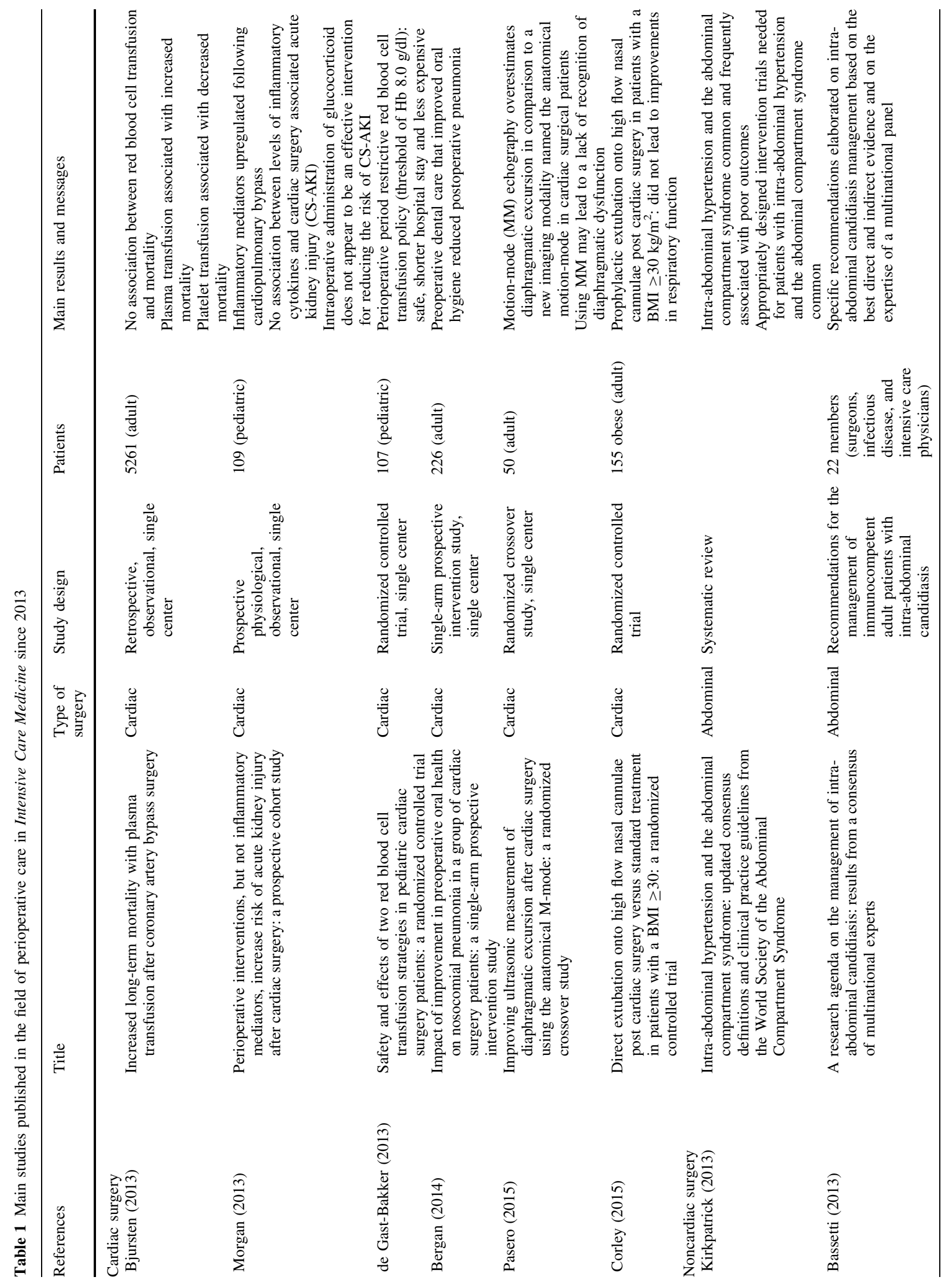




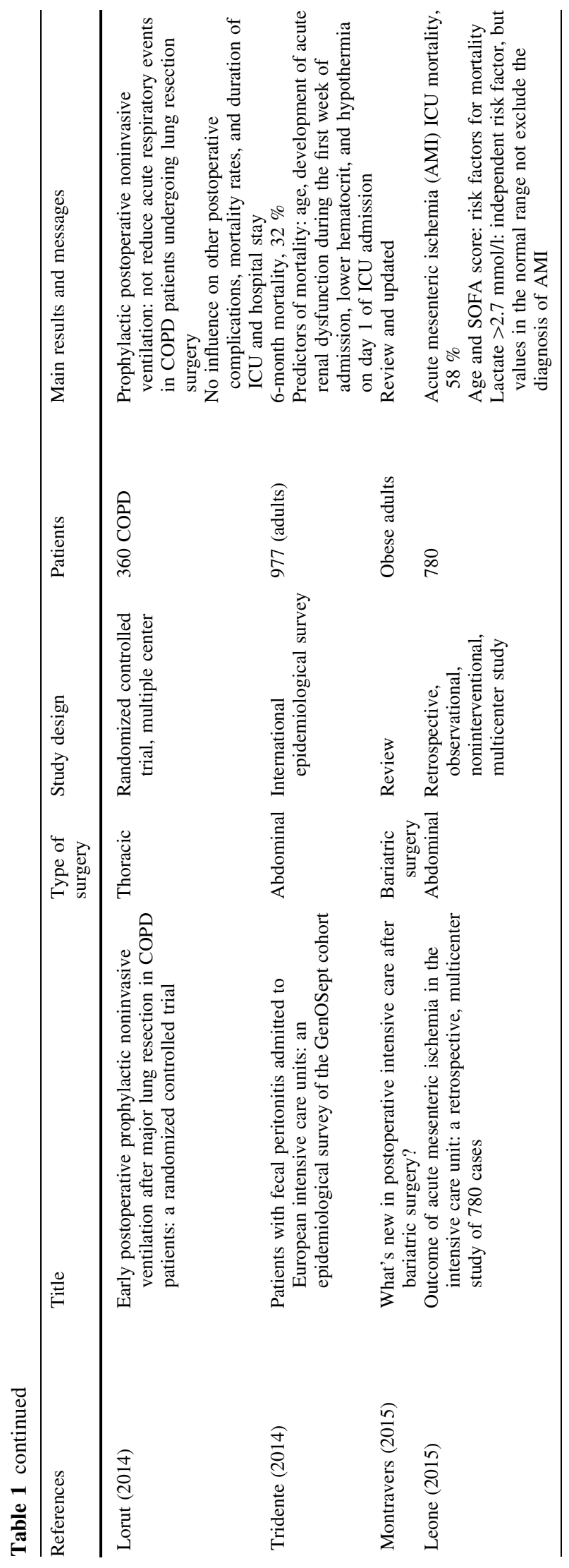

areas continuous monitoring of physiological variables (i.e., hemodynamic and ventilatory function) allows immediate management. Among recent developments are (1) an anesthesia-surgical safety checklist designed to improve team communication [7]; (2) perioperative hemodynamic management in cardiac and noncardiac surgeries [8-11]; (3) ventilatory management by the application of preventive "lung protective ventilation" in abdominal surgery [12, 13]; (4) use of neuromuscular blockade to facilitate mechanical ventilation [14]; and (5) preventive postoperative noninvasive ventilation [15] and (6) anesthesia and pain management using regional anesthesia methods.

ICU management of ARDS patients using lung protective mechanical ventilation including low tidal volume $(6 \mathrm{ml} / \mathrm{kg}$ of ideal body weight, IBW) with moderate to high PEEP $\left(5-15 \mathrm{cmH}_{2} \mathrm{O}\right)$ with or without recruitment maneuver has led to improved outcomes [16]. This lung protective strategy has been transferred from the ICU to the OR care not only in patients with lung injury but also in patients with healthy lungs [13]. For example, it was recently shown that development of postoperative lung injury was dependent on the intraoperative ventilation strategy and, therefore, should be seen as a complication that is potentially preventable by the use of lung protective mechanical ventilation strategies during surgery [13]. The Intraoperative PROtective VEntilation (IMPROVE) trial was a prospective randomized controlled study [12] in which a multifaceted strategy composed of low VT (6-8 $\mathrm{ml} / \mathrm{kg} \mathrm{IBW})$ ventilation, moderate levels of PEEP $\left(6-8 \mathrm{cmH}_{2} \mathrm{O}\right)$, and repeated recruitment maneuver aimed at keeping the lung open was compared with nonprotective ventilation in 400 intermediate to highrisk patients undergoing major abdominal surgery. Consistent with previous findings in similar abdominal procedures, an overall postoperative respiratory failure rate of $12 \%$ was found. Compared with nonprotective ventilation, prophylactic lung-protective ventilation was associated with improved postoperative clinical outcomes, as suggested by a $69 \%$ reduction in the patients requiring intubation or noninvasive ventilation for postoperative respiratory failure (relative risk 0.29 , $95 \%$ CI $0.14-0.61, P=0.001)$.

In the field of perioperative hemodynamic management, Pearse et al. [9] reported the results of a randomized clinical trial exploring the effects of a cardiac output-guided hemodynamic therapy algorithm on the incidence of postoperative complications compared with usual care. OPTIMISE is the largest trial of a perioperative care, cardiac output-guided hemodynamic therapy algorithm. This trial [9] evaluated the clinical effectiveness of a perioperative cardiac output monitoring to guide administration of intravenous fluid and inotropic drugs as part of a hemodynamic therapy algorithm. A total of 734 high-risk patients, aged 
50 years or older, undergoing major gastrointestinal surgery at 17 acute care hospitals in the UK were enrolled. Intervention group patients received intravenous fluid and inotropes according to a cardiac output-guided hemodynamic therapy algorithm. This algorithm was developed for OPTIMISE by an expert group. It was designed to be delivered in the OR and the postanesthetic care unit by both medical and nursing staff, ensuring that critical care admission was not necessary for protocol adherence. The OPTIMISE study was considered as a negative study because it did not reduce a composite outcome of complications and 30-day mortality. However, the authors performed an updated meta-analysis with the inclusion of the OPTIMISE study data and founded that the intervention was associated with a reduction in postoperative complications. One important lesson of both OPTIMISE and IMPROVE is that, while large, randomized controlled trials are never easy to conduct, and they may be easier to complete in the OR than in the ICU as a result of the large numbers of patients at risk. Hopefully the lessons learned in these trials will, in many cases, be applicable in the ICU as well.

Intensive Care Medicine recognizes the importance of the learning relationship between the ICU and the OR. Studies in the perioperative care of critically ill patients have implications not only for this specific population but also for critically ill patients in general. Table 1 reports the main studies published in the field of perioperative care in Intensive Care Medicine since 2013.

Intensive Care Medicine is opening a call for additional, high-quality papers in perioperative medicine mainly in the fields of cardiac, thoracic, abdominal, and neurologic surgeries to be published in these pages. The submission deadline is 1 October 2015.

Conflicts of interest Dr. Jaber reports receiving consulting fees from Dräger, Hamilton, Maquet, and Fisher Paykel. Dr. Citerio reports receiving fees from Codman for educational activities. Dr. Talmor reports receiving grant support from the National Institutes of Health and the Gordon and Betty Moore Foundation.

\section{References}

1. Jammer I, Wickboldt N, Sander M, Smith A, Schultz MJ, Pelosi P, Leva B, Rhodes A, Hoeft A, Walder B, Chew MS, Pearse RM (2015) Standards for definitions and use of outcome measures for clinical effectiveness research in perioperative medicine: European Perioperative Clinical Outcome (EPCO) definitions: a statement from the ESA-ESICM joint taskforce on perioperative outcome measures. Eur J Anaesthesiol 32:88-105

2. Weiser TG, Regenbogen SE, Thompson KD, Haynes AB, Lipsitz SR, Berry WR, Gawande AA (2008) An estimation of the global volume of surgery: a modelling strategy based on available data. Lancet 372:139-144

3. Pearse RM, Moreno RP, Bauer P, Pelosi P, Metnitz P, Spies C, Vallet B, Vincent JL, Hoeft A, Rhodes A (2012) Mortality after surgery in Europe: a 7 day cohort study. Lancet 380:1059-1065

4. Kor DJ, Lingineni RK, Gajic O, Park PK, Blum JM, Hou PC, Hoth JJ, Anderson HL 3rd, Bajwa EK, Bartz RR, Adesanya A, Festic E, Gong MN, Carter RE, Talmor DS (2014) Predicting risk of postoperative lung injury in high-risk surgical patients: a multicenter cohort study. Anesthesiology 120:1168-1181

5. Kor DJ, Talmor D (2013) Anesthesiology and the acute respiratory distress syndrome: an ounce of prevention is worth a pound of cure. Anesthesiology 118:1-4
6. Lassen HC (1953) A preliminary report on the 1952 epidemic of poliomyelitis in Copenhagen with special reference to the treatment of acute respiratory insufficiency. Lancet 1:37-41

7. Haynes AB, Weiser TG, Berry WR, Lipsitz SR, Breizat AH, Dellinger EP, Herbosa T, Joseph S, Kibatala PL, Lapitan MC, Merry AF, Moorthy K, Reznick RK, Taylor B, Gawande AA (2009) A surgical safety checklist to reduce morbidity and mortality in a global population. N Engl J Med 360:491-499

8. Pearse RM, Ackland GL (2012) Perioperative fluid therapy. BMJ 344:e2865

9. Pearse RM, Harrison DA, MacDonald N, Gillies MA, Blunt M, Ackland G, Grocott MP, Ahern A, Griggs K, Scott R, Hinds C, Rowan K (2014) Effect of a perioperative, cardiac output-guided hemodynamic therapy algorithm on outcomes following major gastrointestinal surgery: a randomized clinical trial and systematic review. JAMA 311:2181-2190

10. Pearse RM, Hinds CJ (2006) Should we use central venous saturation to guide management in high-risk surgical patients? Crit Care 10:181

11. Pearse RM, Holt PJ, Grocott MP (2011) Managing perioperative risk in patients undergoing elective non-cardiac surgery. BMJ 343:d5759
12. Futier E, Constantin JM, Paugam-Burtz C, Pascal J, Eurin M, Neuschwander A, Marret E, Beaussier M, Gutton C, Lefrant JY, Allaouchiche B, Verzilli D, Leone M, De Jong A, Bazin JE, Pereira B, Jaber S (2013) A trial of intraoperative low-tidal-volume ventilation in abdominal surgery. N Engl J Med 369:428-437

13. Futier E, Marret E, Jaber S (2014) Perioperative positive pressure ventilation: an integrated approach to improve pulmonary care. Anesthesiology 121:400-408

14. Papazian L, Forel JM, Gacouin A, Penot-Ragon C, Perrin G, Loundou A, Jaber S, Arnal JM, Perez D, Seghboyan JM, Constantin JM, Courant P, Lefrant JY, Guerin C, Prat G, Morange S, Roch A (2010) Neuromuscular blockers in early acute respiratory distress syndrome. N Engl J Med 363:1107-1116

15. Jaber S, Antonelli M (2014) Preventive or curative postoperative noninvasive ventilation after thoracic surgery: still a grey zone? Intensive Care Med 40:280-283

16. Tonelli AR, Zein J, Adams J, Ioannidis JP (2014) Effects of interventions on survival in acute respiratory distress syndrome: an umbrella review of 159 published randomized trials and 29 meta-analyses. Intensive Care Med 40:769-787 